\title{
FOUR FURTHER ANTIBIOTICS RELATED TO OLIVANIC ACID PRODUCED BY STREPTOMYCES OLIVACEUS: FERMENTATION, ISOLATION, CHARACTERISATION AND BIOSYNTHETIC STUDIES
}

\author{
S. J. Box, J. D. Hood and S. R. Spear \\ Beecham Pharmaceuticals Research Division, \\ Brockham Park, Betchworth, Surrey, England \\ (Received for publication July 24, 1979)
}

\begin{abstract}
Four $\beta$-lactam antibiotics with $\beta$-lactamase inhibitory activity MM 22380, MM 22381, MM 22382 and MM 22383 containing the carbapenem nucleus have been isolated from a culture of Streptomyces olivaceus ATCC 31365. Fermentation conditions for their production and methods for their isolation are described. Evidence for a biosynthetic link between these compounds and the previously described olivanic acid derivatives MM 4550, MM 13902 and MM 17880 is presented.
\end{abstract}

The production, isolation and characterisation of three $\beta$-lactam antibiotics with $\beta$-lactamase inhibitory properties, MM 4550, MM 13902 and MM 17880 from Streptomyces olivaceus has previously been described ${ }^{1}$. Further studies with $S$. olivaceus strains capable of producing these compounds have demonstrated the presence of four further structurally related antibiotics all of which have $\beta$-lactamase inhibitory activity. These compounds were designated MM 22380, MM 22381, MM 22382 and MM 22383.

This paper describes fermentation conditions for the production of MM 22380, MM 22381, MM 22382 and MM 22383, a method for their isolation, and preliminary biological and physical properties of the compounds. Studies with a mutant of $S$. olivaceus which provides evidence for a biosynthetic link between these compounds and the previously described olivanic acid derivatives are also described.

\section{Materials and Methods}

\section{Fermentation conditions}

Streptomyces olivaceus was maintained on agar slopes consisting of V8 vegetable juice (Campbells Soups Ltd., Kings Lynn, Norfolk, U.K.) 20\%; Bacto agar (Difco) $2.5 \%$, in deionised water, pH 6.0. After inoculation slopes were incubated at $28^{\circ} \mathrm{C}$ for 1 week before use. A suspension of spores and mycelium in sterile deionised water $(10 \mathrm{ml})$ was prepared from an agar slope contained in a Universal bottle and a portion $(5 \mathrm{ml})$ used to inoculate the seed stage medium $(100 \mathrm{ml})$ contained in a $500-\mathrm{ml}$ Erlenmeyer flask closed with a foam plastic plug. The seed stage medium consisted of glucose $2 \%$, soybean flour (Arkasoy 50, British Arkady Co., Manchester, U.K.) $1 \%$ in deionised water. Inoculated seed stage flasks were incubated at $26^{\circ} \mathrm{C}$ for 48 hours on a rotary shaker.

Portions of the seed stage culture $(1 \mathrm{ml})$ were used to inoculate the fermentation media $(100 \mathrm{ml})$ contained in 500-ml Erlenmeyer flasks. Fermentations were incubated on a rotary shaker at $26^{\circ} \mathrm{C}$, the media had the following compositions:

Medium A: Glucose 2\%, Soybean flour (Arkasoy 50) $1.0 \%, \mathrm{CaCO}_{3} \quad 0.02 \% \mathrm{CoCl}_{2} \cdot 6 \mathrm{H}_{2} \mathrm{O} \quad 0.0001 \%$, $\mathrm{Na}_{2} \mathrm{SO}_{4} 0.05 \%$ prepared in deionised water.

Medium B: As medium A but without $\mathrm{Na}_{2} \mathrm{SO}_{4}$. 
For the biosynthetic studies the $S$. olivaceus mutant was inoculated directly from agar slopes into fermentation medium $\mathrm{C}(70 \mathrm{ml})$ in $250 \mathrm{ml}$ Erlenmeyer flasks.

Medium C: As medium A but with $0.9 \%$ soybean flour.

Medium D: As medium $\mathrm{C}$ but without $\mathrm{Na}_{2} \mathrm{SO}_{4}$.

Fermentations with this culture were incubated at $28^{\circ} \mathrm{C}$ on a rotary shaker.

Where large volumes of culture filtrate were required for isolation of the components the $S$. olivaceus ATCC 31365 was grown in stainless steel fermenters using medium D.

\section{Biosynthetic Studies}

A mutant of $S$. olivaceus designated T1 which synthesises predominantly the two trans isomers, MM 22381 and MM 22383, was used to investigate the biosynthetic relationship of the five cis components. The cis olivanic acid derivatives $(3.5 \mathrm{mg})$ were added to separate fermentation flasks after 48 hours and incubation was continued for 17 hours. Culture filtrates were collected and samples were submitted to DEAE cellulose t.l.c. Further samples of culture filtrate $(20 \mathrm{ml})$ were ion pair extracted with $0.125 \%$ Aliquat 336 (Tricaprylylmethylammonium chloride, General Mills Chemicals Inc., Minneapolis, Minn, U.S.A.) in dichloromethane $(8 \mathrm{ml})$ and back extracted into $0.4 \%$ sodium iodide $(1 \mathrm{ml})$. The extracts were submitted to DEAE cellulose t.1.c. and h.p.l.c. (system B).

\section{Assay Methods}

(1) $\beta$-Lactamase Inhibition Assay

The levels of MM 4550 were determined using an automated $\beta$-lactamase inhibition assay ${ }^{1)}$.

(2) Thin-Layer Chromatography (t.l.c.)

Samples to be assayed $(1 \sim 5 \mu \mathrm{l})$ were loaded onto diethylaminoethyl cellulose t.1.c. sheets (Polygram CEL 300 DEAE, Macherey-Nagel and Co., 516 Duren, Werkstrasse 6-8, Postfach 307, Germany). The chromatograms were developed with $0.1 \mathrm{M} \mathrm{NaCl}$ in $0.05 \mathrm{M}$ potassium phosphate buffer $(\mathrm{pH} 7.0)$ for 4 hours at $4^{\circ} \mathrm{C}$. The antibiotics were detected by laying the t.l.c. plate for 5 minutes on agar seeded with the test organism.

Two test organisms were used:

1) Bacillus subtilis ATCC 6633; after removal of t.1.c. plate the agar was incubated at $28^{\circ} \mathrm{C}$ for 16 hours.

2) Escherichia coli $\mathrm{ESS}^{2)}$ (gift from Prof. A. L. Demain); after removal of the t.l.c. plate the agar was incubated at $37^{\circ} \mathrm{C}$ for 16 hours.

The t.l.c. method was suitable for detecting MM 4550, MM 13902, MM 17880, MM 22380 and MM 22382, the relatively lower antibacterial activity of MM 22381 and MM 22383 meant that these compounds could not be detected. (Rf's of components are shown in Table 2).

(3) High Performance Liquid Chromatography (h.p.1.c.)

The system comprised a Waters Associates Model 6000A solvent delivery system and a U6K injector connected to a Waters $3.9 \times 300 \mathrm{~mm} \mathrm{C}_{18} \mu$ Bondapak reversed phase column (Waters Associates Ltd., Northwich, U.K.). Monitoring was by a Cecil Model 212 uv spectrophotometer (Cecil Instruments, Cambridge, U.K.) using an $8-\mu 1$ flow cell with $10-\mathrm{mm}$ path length at $300 \mathrm{~nm}$, the injection volume was $20 \mu \mathrm{l}$. Two solvent systems were used for elution depending on the test sample:

Eluant A: $0.05 \mathrm{M}$ ammonium phosphate buffer $(\mathrm{pH} 4.7)$ containing $5 \%$ acetonitrile, elution at $2 \mathrm{ml} /$ minute. This system was used for fermentation studies although MM 4550 and MM 17880 could not be conveniently assayed in culture filtrate since they were not separated from the large amounts of interfering compounds eluted near the front of the chromatogram.

Eluant B: $0.05 \mathrm{~m}$ ammonium phosphate buffer ( $\mathrm{pH} 4.7$ ) containing $3 \%$ acetonitrile, elution at $1 \mathrm{ml} /$ minute. This solvent was used for monitoring the ion pair extracts prepared during the biosynthetic studies.

Retention times of the compounds are shown in Table 2.

To aid identification of the olivanic acid derivatives in h.p.l.c. assays, samples were monitored directly and after treatment with a neutral solution of cysteine. The addition of cysteine results in the rapid degradation of the olivanic acid derivatives. The presence of a cysteine degradable peak in the chromatogram with a retention time expected for the derivative confirmed the results. 
Assays of the titres of different metabolites in a fermentation sample was achieved by comparing the peak height for the compound to the peak height given by a known concentration of a standard preparation of the compound under the same chromatographic conditions.

Extraction and Isolation

The following column media were used in the isolation procedure outlined in Fig. 3.

Amberlite IRA 458; acrylic based strongly basic anion-exchange resin.

Amberlite XAD 4; styrene divinylbenzene cross linked polymeric adsorbent, both from Rohm and Haas co., Philadelphia, Pa, U.S.A.

QAE Sephadex A25; strongly basic anion-exchange dextran gel from Pharmacia Fine Chemicals, Uppsala, Sweden.

Diaion HP20; $\quad$ styrene divinylbenzene cross linked polymeric adsorbent from Mitsubishi Chemical Industries, Tokyo, Japan.

Biogel P2; $\quad$ polyacrylamide gel from Bio Rad Laboratories, Bromley, Kent, U.K.

\section{Results}

Fermentation and Isolation Studies

When Streptomyces olivaceus ATCC 31365 was grown in fermentation medium A, the presence of antibiotic zones with chromatographic properties consistent with MM 13902 and MM 17880 were detected using the diethylaminoethyl cellulose t.l.c. method with Bacillus subtilis as test organism. Assays with the $\beta$-lactamase inhibition method showed the level of MM 4550 to be 0.9 $\mu \mathrm{g} / \mathrm{ml}$, which was below the level of detection of

Fig. 1. Thin-layer chromatography of culture filtrate (72 hour) of $S$. olivaceus.

Support: DEAE cellulose

Eluant: $\quad 0.1 \mathrm{M} \mathrm{NaCl}$ in $0.05 \mathrm{M}$ potassium phosphate buffer $(\mathrm{pH} 7)$

Detection: Bioautography on B. subtilis

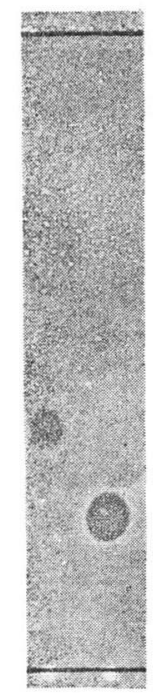

Solvent front
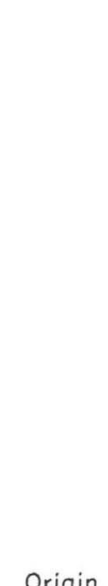
MM17880 MM13902

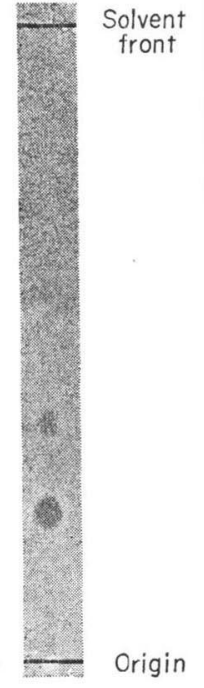

Medium A

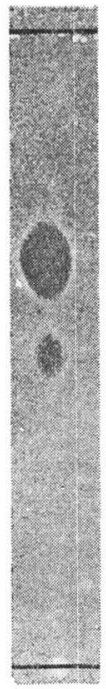

Medium B
Fig. 2. High performance liquid chromatography of culture filtrate (72 hours) from $S$. olivaceus.

Chromatographic conditions: $\mathrm{C}_{18}$ reversed phase column, eluant $0.05 \mathrm{M}$ ammonium phosphate (pH 4.7) containing $5 \%$ acetonitrile. (Solvent A) Flow rate $2 \mathrm{ml} / \mathrm{min}$; monitor (uv) at $300 \mathrm{~nm}$.

* Peaks degraded on cysteine treatment (see Materials and Methods)

A: Culture grown in medium A.

B: Culture grown in medium B.

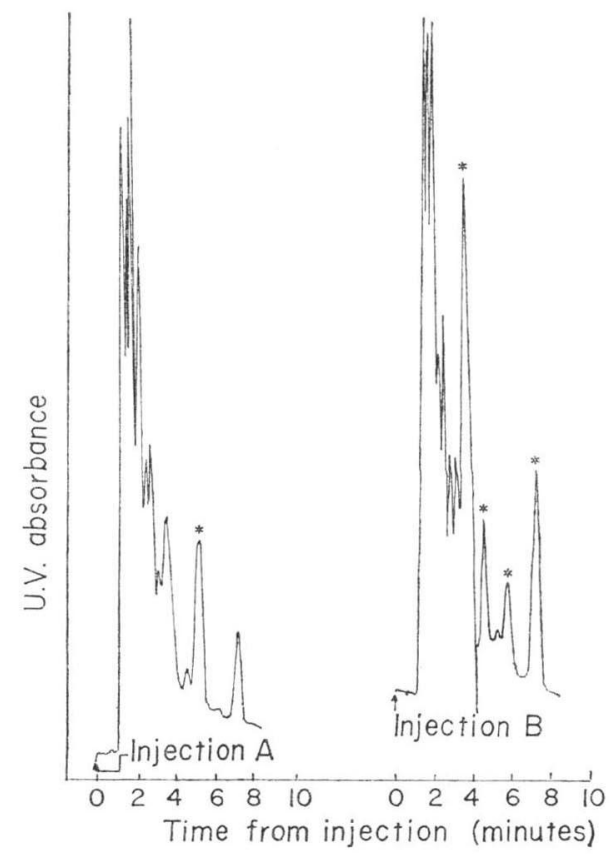


the t.l.c. method. When the culture was grown in the medium without sodium sulphate (Medium B) there was a marked change in the antibiotics produced, MM 13902 and MM 17880 could not be detected, and two new antibiotic zones were observed at $\mathrm{Rf} 0.51$ and $\mathrm{Rf} 0.66$. In this medium the level of MM 4550 was assayed at $0.3 \mu \mathrm{g} / \mathrm{ml}$. The results of t.1.c. analysis of 72 hours fermentation samples from media A and B are shown in Fig. 1. When the same culture filtrate samples were sub-

Fig. 3. Isolation procedure for MM 22380, MM 22381, MM 22382 and MM 22383

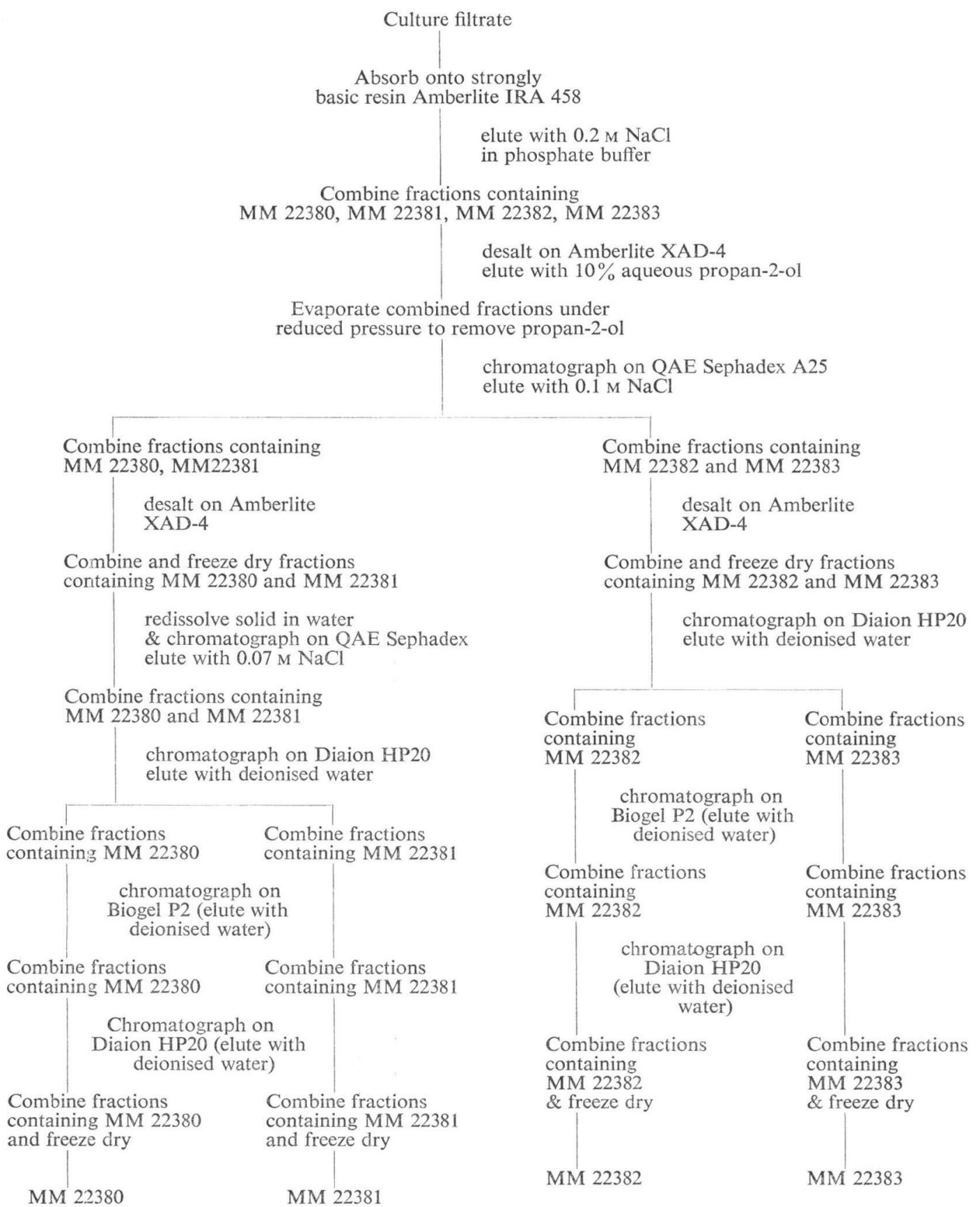


mitted to h.p.1.c. the resulting chromatograms (Fig. 2) showed the presence of four new cysteine degradable components in medium B. The four new components detected in the h.p.l.c. analysis were designated MM 22380, MM 22381, MM 22382 and MM 22383, titres were in the range 1 to 5 $\mu \mathrm{g} / \mathrm{ml}$ for each compound.

Isolation of MM 22380, MM 22381, MM 22382 and MM 22383 was achieved by processing culture filtrate yielded by fermentation of $S$. olivaceus ATCC 31365 in a stainless steel fermenter. The culture filtrate was submitted to the extraction procedure outlined in Fig. 3. This process yielded MM 22380, MM 22381, MM 22382 and MM 22383 in substantially pure form as their sodium salts. Their structures have been determined ${ }^{33}$ and are shown in Fig. 4. The compounds are two isomeric pairs of antibiotics with structures related to those of the previously described olivanic acid derivatives MM 4550, MM 13902 and MM 17880.

Fig. 4. Structures of antibiotics detected in Streptomyces olivaceus.<smiles>[R6]C(C)[C@H]1C(=O)n2c1cc(SCCNC(C)=O)c2C(=O)O</smiles><smiles>CC(=O)N/C=C/S(=O)C1=C(C(=O)O)N2C(=O)C(C(C)O)C2C1</smiles>

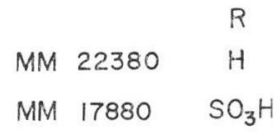

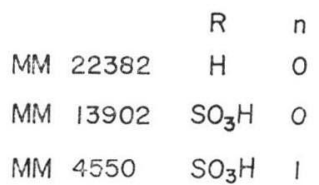<smiles>CC(=O)NCCSC1=C(C(=O)O)N2C(=O)[C@H](C(C)O)[C@H]2C1</smiles>

MM 2238<smiles>CC(=O)N/C=C/SC1=C(C(=O)O)N2C(=O)[C@H](C(C)O)[C@H]2C1</smiles>

MM 22383

Properties of MM 22380, MM 22381, MM 22382 and MM 22383

Some spectral data of the compounds are shown in Table 1 and chromatographic properties in Table 2.

Each of the four components show a broad spectrum of antibacterial activity, typical minimum

Table 1. UV and IR spectral characteristics of MM 22380, MM 22381, MM 22382 and MM 22383.

\begin{tabular}{c|c|c|c|c}
\hline & MM 22380 & MM 22381 & MM 22382 & MM 22383 \\
\hline UV (max) nm & $298(\epsilon=8,131)$ & $301(\epsilon=7,930)$ & $308(\epsilon=13,627)$ & $309(\epsilon=13,933)$ \\
& & & $228(\epsilon=13,290)$ & $229(\epsilon=13,933)$ \\
IR (KBr disc) & 1750 & 1750 & 1750 & 1750 \\
$\mathrm{~cm}^{-1}$ & $1630(\mathrm{sh})$ & $1735(\mathrm{sh})$ & 1675 & 1670 \\
& 1590 & 1590 & $1590 \sim 1620$ & $1590 \sim 1620$ \\
\hline
\end{tabular}


Table 2. Chromatographic properties of olivanic acid derivatives.

\begin{tabular}{|c|c|c|c|}
\hline & \multirow{2}{*}{$\begin{array}{l}\text { Rf on DEAE } \\
\text { cellulose } \\
\text { thin-layer } \\
\text { chromato- } \\
\text { graphy* }\end{array}$} & \multicolumn{2}{|c|}{$\begin{array}{c}\text { Retention time } \\
\text { (mins) } \\
\text { on reversed phase } \\
\text { h.p.l.c. }{ }^{\dagger}\end{array}$} \\
\hline & & $\begin{array}{c}\text { Solvent } \\
\text { A }\end{array}$ & $\begin{array}{c}\text { Solvent } \\
\text { B }\end{array}$ \\
\hline MM 4550 & 0.33 & 2.2 & 5.7 \\
\hline MM 13902 & 0.20 & 5.4 & 21.2 \\
\hline MM 17880 & 0.33 & 3.0 & 9.6 \\
\hline MM 22380 & 0.75 & 3.9 & 12.4 \\
\hline MM 22381 & n.d. & 5.2 & 18.0 \\
\hline MM 22382 & 0.57 & 6.6 & 22.8 \\
\hline MM 22383 & n.d. & 8.0 & 29.0 \\
\hline
\end{tabular}

* Eluted with $0.1 \mathrm{M} \mathrm{NaCl}$ in $0.05 \mathrm{M}$ potassium phospliate buffer ( $\mathrm{pH} 7.0$ ).

$\dagger$ H.p.l.c. on $3.9 \times 300 \mathrm{~mm}$ Waters $\mathrm{C}_{18} \mu$ Bondapak column.

Solvent A: $\quad 0.05 \mathrm{M}$ ammonium phosphate buffer containing $5 \%$ acetonitrile $(\mathrm{pH} 4.7)$ at $2 \mathrm{ml} / \mathrm{minute}$.

Solvent B: $\quad 0.05 \mathrm{M}$ ammonium phosphate buffer containing $3 \%$ acetonitrile $(\mathrm{pH} 4.7)$ at $1 \mathrm{ml} /$ minute.

n.d. $=$ not detected
Table 3. Antibacterial activity of MM 22380, MM 22381, MM 22382 and MM 22383.

\begin{tabular}{|c|c|c|c|c|}
\hline \multirow{2}{*}{ Organism } & \multicolumn{4}{|c|}{$\begin{array}{l}\text { Minimum inhibitory } \\
\text { concentration }(\mu \mathrm{g} / \mathrm{ml})\end{array}$} \\
\hline & $\underset{22380}{\mathrm{MM}}$ & $\begin{array}{c}\mathrm{MM} \\
22381\end{array}$ & $\begin{array}{c}\text { MM } \\
22382\end{array}$ & $\begin{array}{c}\text { MM } \\
22383\end{array}$ \\
\hline $\begin{array}{l}\text { Escherichia coli } \\
0111\end{array}$ & $<0.5$ & 4.0 & $<0.2$ & 8.0 \\
\hline $\begin{array}{l}\text { Escherichia coli } \\
\text { JT39 }\end{array}$ & 16.0 & 4.0 & 4.0 & 8.0 \\
\hline $\begin{array}{l}\text { Enterobacter } \\
\text { cloacae N1 }\end{array}$ & 4.0 & 16.0 & 4.0 & 16.0 \\
\hline $\begin{array}{l}\text { Klebsiella } \\
\text { aerogenes A }\end{array}$ & 1.0 & 4.0 & 0.5 & 8.0 \\
\hline $\begin{array}{l}\text { Proteus mirabilis } \\
\quad 972\end{array}$ & 0.5 & 8.0 & 0.2 & 31.0 \\
\hline $\begin{array}{l}\text { Pseudomonas } \\
\text { aeruginosa } \mathrm{A}\end{array}$ & 31.0 & 125 & 125 & 125 \\
\hline $\begin{array}{l}\text { Staphylococcus } \\
\text { aureus Oxford }\end{array}$ & 0.5 & 4.0 & 0.5 & 8.0 \\
\hline $\begin{array}{l}\text { Staphylococcus } \\
\text { aureus Russell }\end{array}$ & 0.5 & 4.0 & 0.5 & 8.0 \\
\hline $\begin{array}{l}\text { Streptococcus } \\
\quad \text { faecalis I }\end{array}$ & 1.0 & 16.0 & 1.0 & 31.0 \\
\hline $\begin{array}{l}\text { Streptococcus } \\
\quad \text { pyogenes CN10 }\end{array}$ & $<0.2$ & 0.5 & $<0.2$ & 2.0 \\
\hline
\end{tabular}

Tests were carried out by serial dilution in nutrient broth by microtitre. Inoculum was prepared by dilution of an overnight broth culture to give the equivalent of approximately $10^{6}$ cells $/ \mathrm{ml}$. inhibitory concentrations are shown in Table 3. The compounds also exhibit potent $\beta$-lactamase inhibitory activity, results obtained with a number of cell-free $\beta$-lactamase preparations are given in Table 4.

Biosynthetic Studies

Transformation of cis olivanic acids MM 22380 and MM 22382 by the S. olivaceus blocked mutant T1 was demonstrated by thin-layer chromatography of culture filtrates as shown in Fig. 5. The two trans
Table 4. $\beta$-Lactamase inhibitory activity of MM 22380, MM 22381, MM 22382 and MM 22383.

\begin{tabular}{l|c|c|c|c|c}
\hline \multirow{3}{*}{ Compound } & \multicolumn{5}{|c}{$\mathrm{I}_{50}(\mu \mathrm{g} / \mathrm{ml})$} \\
\cline { 2 - 7 } & $\begin{array}{c}\text { Substrate, } \\
\text { cephaloridine }\end{array}$ & \multicolumn{3}{|c}{$\begin{array}{c}\text { Substrate, } \\
\text { benzyl penicillin }\end{array}$} \\
\cline { 2 - 7 } & $\begin{array}{c}\text { Entero- } \\
\text { bacter } \\
\text { cloacae } \\
\text { P99 }\end{array}$ & $\begin{array}{c}\text { Pseudo- } \\
\text { monas } \\
\text { aerugi- } \\
\text { nosa A }\end{array}$ & $\begin{array}{c}\text { Proteus } \\
\text { mirabilis }\end{array}$ & $\begin{array}{c}\text { Escheri- } \\
\text { chia } \\
\text { coli }\end{array}$ & $\begin{array}{c}\text { Staphylo- } \\
\text { coccus } \\
\text { aureus } \\
\text { Russell }\end{array}$ \\
\hline MM 22380 & 0.02 & 4.0 & 0.1 & JT4 & $>2.0$ \\
MM 22381 & 0.04 & 4.0 & $>2.0$ & 0.28 & $>2.0$ \\
MM 22382 & 0.02 & 3.0 & 0.04 & $>2.0$ & 0.08 \\
MM 22383 & 0.04 & 4.0 & 0.4 & 0.1 & $>2.0$ \\
\hline
\end{tabular}

$\mathrm{I}_{50}$ values were determined by the method described by $\mathrm{C}$. ReAding and P. HePburn ${ }^{4}$ ) olivanic acids, MM 22381 and MM 22383 produced by the mutant were not detected by the t.l.c./ bioautographic method due to their relatively low antibacterial activity. Apart from the zones of inhibition due to the added compound two new zones at Rf 0.20 and 0.33 were detected in both test samples. A zone of Rf 0.20 is characteristic of MM 13902 but two olivanic acids, MM 4550 and MM 17880, have an Rf value of 0.33. Resolution of these compounds was achieved by h.p.l.c. using system B after concentration and partial purification via ion pair extraction. The results in Table 5 show the presence of both MM 4550 and MM 17880 in the sample derived from MM 22380, but only 
Table 5. High performance liquid chromatography of partially purified extracts derived from the $S$. olivaceus blocked mutant after incubation with olivanic acid derivatives.

\begin{tabular}{c|c|c}
\hline \multirow{2}{*}{ Compound added } & \multicolumn{2}{|c}{ Compound detected } \\
\cline { 2 - 3 } & $\begin{array}{c}\text { MM 4550 } \\
\text { Rt 5.7 min }\end{array}$ & $\begin{array}{c}\text { MM 17880 } \\
\text { Rt 9.6 min }\end{array}$ \\
\hline Control & - & - \\
MM 22380 & + & + \\
MM 22382 & + & - \\
MM 17880 & - & + \\
MM 13902 & - & - \\
\hline
\end{tabular}

+ Compound detected

- Compound not detected

H.p.l.c. on $\mathrm{C}_{18} \mu$ Bondapak reversed phase column eluted with $0.05 \mathrm{M}$ ammonium phosphate buffer $(\mathrm{pH}$ 4.7 ) containing $3 \%$ acetonitrile.

MM 4550 in the sample derived from MM 22382. Addition of MM 17880 and MM 13902 to the blocked mutant resulted in the detection of the added compound only. Culture filtrate removed from a control flask at 48 hours was unable to effect the transformations on $\mathrm{MM}$ 22380 and MM 22382 observed with a growing culture.
Fig. 5. Thin-layer chromatography of culture filtrates derived from the $S$. olivaceus blocked mutant incubated with olivanic acid derivatives.

Support: DEAE cellulose

Solvent: $\quad 0.1 \mathrm{M} \mathrm{NaCl}$ in $0.05 \mathrm{M}$ potassium phosphate buffer ( $\mathrm{pH} \mathrm{7)}$

Assay organism: E. coli ESS

Sample A: $\quad S$. olivaceus blocked mutant T1 control

Sample B: $\quad S$. olivaceus blocked mutant T1 + MM 22380

Sample C: S. olivaceus blocked mutant $\mathrm{T} 1+\mathrm{MM} 22382$

Sample D: $\quad$ MM 4550

Sample E: $\quad$ MM 17880

Sample F: $\quad$ MM 13902

Sample G: $\quad$ MM 22380

Sample H: $\quad$ MM 22382

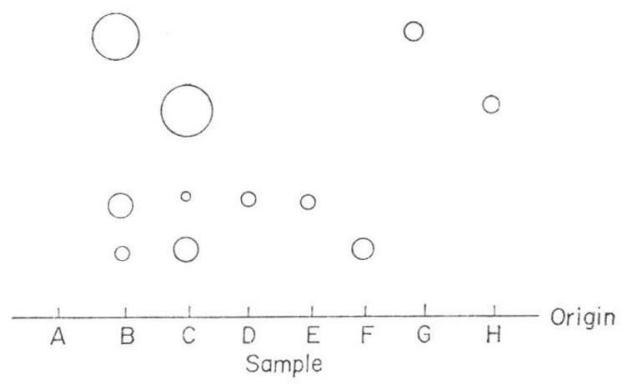

\section{Discussion}

Fermentation studies with Streptomyces olivaceus ATCC 31365 demonstrated that substantial changes in the antibiotics produced by the culture could be effected by the presence or absence of sodium sulphate in the medium. Evaluation of these changes using thin-layer chromatography-bioautographic techniques demonstrated the presence of two previously unidentified antibiotic components when sulphate was absent from the medium. The application of h.p.l.c. to the same culture filtrate samples demonstrated the presence of four rather than two new olivanic acid derivatives. These results demonstrated the usefulness of the extremely high resolving power of h.p.l.c. for the separation of series of closely related antibiotics even in fermentation samples. In this case the use of a physical property of the compound, u.v. absorbance, enabled the detection of all four components despite the relatively low antibacterial activity of two members of the series.

Although ion-exchange resins played a most important role in the extraction and isolation of MM 22380, MM 22381, MM 22382 and MM 22383, perhaps the most interesting aspect of the isolation procedure was the resolution of the isomeric pairs of antibiotics. Separation of such closely related components might have been expected to be particularly difficult but was successfully achieved using the polymeric adsorbent Diaion HP20.

Examination of the structures of the olivanic acid derivatives produced by $S$. olivaceus clearly demonstrates the structural relationship between the compounds. MM 17880 and MM 13902 are the sulphate esters of MM 22380 and MM 22382 respectively. MM 22381 and MM 22383 are differentiated from the other olivanic acids in their trans-stereochemistry at the $\beta$-lactam. The observations that the 
addition of sodium sulphate to the fermentation medium stimulated the production of the sulphated antibiotics with concomitant reduction in MM 22380, MM 22381, MM 22382 and MM 22383 suggested all components shared a common biosynthetic pathway. Further evidence for the biosynthetic relationship of the cis-compounds was obtained using the feeding experiments with the S. olivaceus blocked mutant T1. The addition of MM 22382 resulted in the production of MM 13902 and MM 4550 , suggesting MM 22382 is the direct precursor of MM 13902. Since the addition of MM 13902 did not result in the formation of MM 4550, this compound could be formed via an alternative pathway from MM 22382. MM 22380 was converted into the three sulphates suggesting that this compound is indeed the direct precursor of MM 17880. Furthermore since there was no evidence for the conversion of MM 17880 to MM 13902, MM 22380 was probably transformed to MM 22382 before the sulphation stage to MM 13902. These results are summarised in Scheme 1.

Scheme 1. Proposed biosynthetic relationship of the cis-olivanic acids

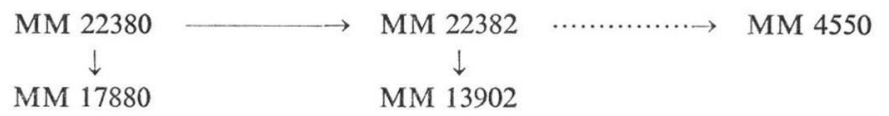

Experiments with the $S$. olivaceus blocked mutant $\mathrm{T} 1$ have not clarified the relationship between the trans-olivanic acid derivatives and the cis-compounds.

A number of other antibiotics with the carbapenem nucleus have been described. Thienamycin, $\mathrm{N}$-acetylthienamycin and $\mathrm{N}$-acetyldehydrothienamycin ${ }^{5)}$ are produced by Streptomyces cattleya, all these compounds differ in at least the stereochemistry at position 8 from the olivanic acid derivatives isolated from S. olivaceus. A series of compounds produced by strains of Streptomyces flavogriseus, epithienamycins $\mathrm{A}, \mathrm{B}, \mathrm{C}$, and $\mathrm{D}^{6,7)}, 890 \mathrm{~A}_{9}{ }^{8)}$ and $890 \mathrm{~A}_{10}{ }^{9)}$, have the same gross structures as the olivanic acid derivatives, excluding MM 4550. Streptomyces cremeus var. auratilis has been reported to produce a related metabolite PS-5 $5^{10,11}$ having an ethyl group at position 6 with the acetamidoethanethiol side-chain at position 3 .

\section{Acknowledgement}

The authors are indebted to G. HANSCOMB for large scale fermentations, M. Verrall and K. Robins for large scale extraction, J. Hodgson for providing the blocked mutant, Mrs. J. Christensen for assistance with biosynthetic studies, C. READING for $\beta$-lactamase inhibition data and M. BASKER for antibacterial data. We also gratefully acknowledge the advice and support received from Dr. A. G. BRown throughout his work.

\section{References}

1) Hood, J. D.; S. J. Box \& M. S. Verrall: Olivanic acids, a family of $\beta$-lactam antibiotics with $\beta$-lactamase inhibitory properties produced by Streptomyces species. II. Isolation and characterisation of MM 4550, MM 13902 and MM 17880 J. Antibiotics 32: 295 304, 1979

2) Koshaka, M. \& A. L. Demain: Conversion of penicillin $\mathrm{N}$ to cephalosporin(s) by cell-free extracts of Cephalosporium acremonium. Biochem. Biophys. Res. Commun. 70: 465 473, 1976

3) Brown, A. G.; D. F. Corbett, A. J. Eglington \& T. T. Howarth: Structures of olivanic acid derivatives MM 22380, MM 22381, MM 22382 and MM 22383; four new antibiotics from Streptomyces olivaceus J. Antibiotics 32: 961 963, 1979

4) Reading, C. \& P. Hepburn: The inhibition of staphylococcal $\beta$-lactamase by clavulanic acid. Biochem. J. 179: $67 \sim 76,1979$

5) Kahan, J. S.; F. M. Kahan, R. Goegelman, S. A. Currie, M. Jackson, E. O. Stapley, T. W. Miller, A. K. Miller, D. Hendlin, S. Mochales, S. Hernandez, H. B. Woodruff \& J. Birnbaum: Thienamycin, a new $\beta$-lactam antibiotic. I. Discovery, taxonomy, isolation and physical properties. J. Antibiotics 32: $1 \sim 12,1979$

6) Stapley, E. O.; P. Cassidy, S. A. Currie, D. Daoust, R. Goegelman, S. Hernandez, M. Jackson, J. M. Mata, A. K. Miller, R. L. Monaghan, J. B. Tunac, S. B. Zimmerman \& D. Hendlin: Epithienamycins: Biological studies of a new family of $\beta$-lactam antibiotics. Abstract 80,17 th Intersci. Conf. Antimicrobial Agents and Chemotherapy, New York, N.Y., 1977 
7) Cassidy, P. J.; E. O. Stapley, R. T. Goegelman, T. W. Miller, B. H. Arison, G. Albers-Schonberg, S. B. Zimmerman \& J. Birnbaum: Epithienamycins. Isolation and identification. Abstract 81, 17th Intersci. Conf. Antimicrobial Agents and Chemotherapy, New York, N.Y., 1977

8) Merck and Co., Inc.: Antibiotic $890 \mathrm{~A}_{9}$ by fermentation. Ger. Offen. 2,751,260. May 24, 1978

9) Merck and Co., Inc.: Antibiotic $890 \mathrm{~A}_{10}$. Ger. Offen. 2,751,303. May 18, 1978

10) Okamura, K.; S. Hirata, Y. Okumura, Y. Fukagawa, Y. Shimauchi, K. Kouno, T. Ishikura \& J. Lein: PS-5, a new $\beta$-lactam antibiotic from Streptomyces. J Antibiotics 31: 480 482, 1978

11) Okamura, K.; S. Hirata, A. Koki, K. Hori, N. Shibamoto, Y. Okumura, O. Okabe, R. Okamoto, K. Kouno, Y. Fukagawa, Y. Shimauchi, T. Ishikura \& J. Lein: PS-5, a new $\beta$-lactam antibiotic. I. Taxonomy of the producing organism, isolation and physico-chemical properties. J. Antibiotics 32: 262 271,1979 